\title{
Faces do comum na comunicação: da partilha à disjunção
}

Thales Vilela Lelo

Resumo: Uma definição recorrente de comunicação invoca a raiz etimológica do termo, que, de procedência no latim, designa uma atividade realizada conjuntamente, proveniente de uma situação de encontro social. Esse sentido originário da palavra se difundiu em uma parcela significativa dos estudos da área, indicando que a comunicação seria produto de uma ação em comum. Nesse artigo, as implicações dessa forma de apreensão das práticas interacionais serão contrastadas com outra maneira de perceber a partilha inerente à comunicação, acionada através de uma fonte etimológica distinta, ligada à disjunção e aos riscos e entraves que permeiam os processos de coordenação conjunta de ações. Argumenta-se que essa abordagem pode enriquecer uma visada crítica no âmbito dos estudos em Comunicação.

Palavras-chave: modelos comunicacionais; mundo comum; partilha; dissenso.

Abstract: Faces of common in communication: from sharing to disjunction - A recurrent definition of communication relies on the etymological root of the term, whose origin in Latin means an activity accomplished together, from a situation of social meeting. This original meaning of the word has spread in a significant parcel of studies in this area, indicating that communication would be the product of a common action. In this paper, the implications of this form of grasping the interactional practices will be contrasted with another way to realize the sharing inherent in communication, driven by a distinct etymological root, linked to the disjunction and to the risks and obstacles that permeate the processes of joint coordination of actions. It is argued that this approach can enrich a critical perception in the field of communication studies.

Keywords: communication models; common world; partition; dissent.

\section{Introdução}

No âmbito dos estudos em Comunicação, a apreensão das características intrínsecas aos processos interacionais deriva sobremaneira da forma como a noção mesma de comunicação é entendida. Williams, em seu dicionário de palavras-chave acerca da cultura e da sociedade, define a palavra, em seu sentido moderno, "como tornar comum 
a muitos, compartilhar" (2003, p.75). Mas essa acepção do termo, que aparece na linguagem francesa na segunda metade do século XIV, sofre notáveis modificações, indo do participar de uma notícia do século XVI ao transmitir doenças - até alcançar os vasos comunicantes do XVIII, segundo Winkin (1998). Na língua inglesa, a trajetória é análoga, e o desenvolvimento dos meios de transporte e de condução de eletricidade também no século XVII foi o carro-chefe da abstração geral de comunicação como sinônimo de canais, estradas e ferrovias. O partilhar, diacronicamente, torna-se sentido secundário de usos que circulam no limiar do transmitir. Assim, no início do XIX, não só vias de transporte são meios de comunicação, mas também os primeiros sistemas telegráficos eletromagnéticos, os telefones, as mídias... A pluralização da concepção de transferência de um meio para o outro é disseminada a partir do advento da globalização no final do século XIX e princípio do XX, como discorre Thompson (2009).

Essa divergência etimológica na acepção de comunicação, oscilando da partilha à transferência, ampara uma gama ampla de debates que procuram distinguir um entendimento matemático-informacional da comunicação de uma abordagem dialógica, relacional e praxiológica. O sentido de comunicação ligado à transmissão se caracteriza por unidirecionalidade, pelo caráter intencional do processo e pela boa decodificação da mensagem (com diminuição progressiva dos valores de ruído), tendo a língua como ferramenta apropriada à designação de entidades do mundo e necessária à construção de representações adequadas de suas propriedades. Dentre os autores que teorizaram a partir desse modelo telegráfico do processo comunicativo, os mais mencionados são Claude Shannon e Warren Weaver (particularmente em seu artigo A Mathematical Theory of Communication, de 1948) e o linguista estruturalista Roman Jakobson.

Levando em consideração que já há uma ampla literatura que parte desse desacordo etimológico - de modo que se coloca hoje como superada ou em vias de superação, ao menos no âmbito epistemológico, a concepção transmissiva da comunicação -, interessa-nos rastrear outro tipo de discussão que parece emergir já mais recentemente, dessa vez descortinando, da origem do termo, dois significados distintos: um ligado à conjunção e outro à disjunção.

Em uma primeira seção do artigo, a raiz da palavra comunicação será retomada em seu sentido de ação em comum, e será possível depreender as implicações dessa leitura na compreensão dos processos interacionais através do resgate das conceituações de autores de referência para os estudos em Comunicação: o pragmatismo de John Dewey, a antropologia filosófica de Francis Jacques e o modelo praxiológico de Louis Quéré.

Logo em seguida, no segundo tópico, as implicações dessa visada relacional da comunicação serão contrastadas com outra maneira de perceber o comum inerente aos processos interacionais: um comum fraturado, cindido entre as premissas que governam uma ação mutuamente referida (que presumem compreensão recíproca e certa igualdade de entendimento), e as geometrias e formas de distribuir os termos do comum que 
hierarquizam os corpos e mesmo engolfam seus intervalos sob o ideal de uma aliança entre supostos parceiros. Nessa perspectiva, propõe-se que a fictícia neutralidade e naturalidade do comum deve ser desmantelada por práticas provisórias e conflitivas de verificação do comum e daqueles que até então eram autorizados a figurar e atuar nele (algo que extrapola a discordância de opiniões de aliados em comunhão). Essas considerações serão amparadas, sobretudo, por conceituações que tracejam em direção a uma agonística comunicacional, presentes nas obras do filósofo francês Jacques Rancière.

\section{Da partilha no agir em comum}

No que diz respeito à leitura da noção de comunicação pelo prisma da partilha, é pertinente retomar a leitura feita em Martino (2001) que, em um texto dedicado a esmiuçar a polissemia de acepções da palavra, a concebe, em sua origem no latim (communicatio), como uma atividade realizada conjuntamente, e atribui esse primeiro sentido ao vocabulário religioso que a gerou. Segundo esse autor, no cristianismo antigo, em que a vida eclesiástica era pautada por contemplação e isolamento - elementos considerados essenciais para o contato com Deus -, havia duas formas preponderantes de interpretar a conjugação dessas virtudes: de um lado, os anacoretas adotavam uma vida em completa solidão; de outro, os cenobitas se devotavam a uma experiência em comunidade, seja em conventos ou mosteiros (que também eram conhecidos como cenóbios, o que, em uma tradução livre, significaria lugar onde se vive em comum). Nos mosteiros dos cenobitas desponta uma prática que foi nomeada como communicatio, que seria o ato de tomar a refeição da noite em comum, "cuja peculiaridade evidentemente não recai sobre a banalidade do ato de 'comer', mas de fazê-lo 'juntamente com outros', reunindo então aqueles que se encontravam isolados" (MARTINO, 2001, p.13). O propósito dessa prática era o de romper o isolamento em que viviam os monges e sua originalidade impunha que uma nova palavra fosse forjada para exprimir o ato.

Desse resgate etimológico, Martino (2001) infere um conjunto de implicações para o entendimento dos processos interacionais: 1) comunicação designa relações onde hajam elementos que se destacam de um fundo de isolamento; 2) há a intenção de romper o isolamento; 3) há uma realização em comum. Cabe destacar que quando se menciona que o ato comunicativo envolve algo em comum, essa partilha não é da ordem de uma similaridade de características ou propriedades entre elementos díspares, já que a comunicação não diz respeito à essência ou aos atributos das coisas. Do mesmo modo, o comum não denota a pertença a uma mesma comunidade, ou mesmo a participação em um hábito ou tarefa grupal. Na própria etimologia, Martino (2001) frisa que a ideia de comunicação já está vinculada ao produto de um encontro social. Esse entendimento também é manifesto pela decomposição do termo nos radicais comum + ação, onde o significado da ação em comum é o de uma ação realizada sobre outrem em uma situação de encontro. 
Embora a ideia de comunhão ou aliança religiosa oriunda da acepção original de comunicação resida em poucos autores, a exemplo da filosofia do diálogo de Martin Buber (2003) (que advoga que o contato com o divino acontece por meio de uma interlocução genuína com a alteridade), a percepção do processo comunicativo como uma ação em comum ou mutuamente referenciada ampara direta ou indiretamente uma vasta cadeia de perspectivas teóricas ${ }^{1}$, de modo que seria impossível delinear em minúcias como, em cada vertente, é conformada tal acepção de comunicação. Apesar disso, é possível delinear alguns dos componentes centrais dessa linha de compreensão: 1) a construção comum e contextual do sentido; 2) a fundação da identificação subjetiva através da interlocução; 3) a determinação relativa do mundo comum por meio de modelagem mútua.

Na obra Experiência e Natureza, John Dewey define comunicação como aquilo que torna possível a participação e o ato de compartilhar. Segundo o autor, pela comunicação os eventos se tornam objetos (coisas que possuem significado) que podem fornecer informações em um contexto no qual adquirem novos modos de operação e propriedades. Dewey (1980) argumenta que a atividade humana é participante, na medida em que as ações comunicativas são condicionadas pela percepção da situação que serve de espaço comum aos interlocutores, levando à internalização das possíveis respostas dos outros que estão acolhidos em um mesmo contexto de intercâmbio. O argumento desse filósofo estadunidense leva à constatação de que, se todas as coisas possuem uma potencial comunicabilidade, ou seja, se todas as coisas podem fazer parte do discurso, então um fenômeno possui sentido em função daquilo que é possível na relação com ele. Em outras palavras, na ação em comum que caracteriza o fenômeno comunicativo desponta o significado como "aquisição de significação pelas coisas enquanto tornando possível e realizando a cooperação co-participada" (DEWEY, 1980, p.37).

A emergência da identificação pessoal dos sujeitos (parceiros de interlocução) pela via das interações é o segundo elemento de composição de uma visão relacional da comunicação. O filósofo Francis Jacques (1982) se dedica a essa questão ao definir um primado relacional para as interações humanas. Segundo ele, a relação é uma realidade emergente que constitui os termos que a compõem. A relação é primitiva e locutor e destinatário são conceitos derivados. Destarte, a interlocução é considerada não só como uma condição necessária à emergência do sentido, mas também, consequentemente, como uma forma a priori da experiência.

Sendo a relação o primado na acepção de Jacques (1982), sugere-se que, pela atividade conjunta, cooperativa, de transação semântica, é que se desenharia a formação subjetiva. Para esse autor, o sujeito não é constituído, ele se institui como agente da comunicação e resulta de um trabalho de identificação contínuo que está subordinado a metamorfoses e à pesquisa de princípios que orientam as escolhas e determinam

1 A exemplo do pragmatismo, da Escola de Chicago, da estética da recepção, da segunda geração da Teoria Crítica, dos Estudos Culturais, entre outros. 
as responsabilidades assumidas. Deriva-se desse ponto de vista que a identificação é um longo esforço nunca encerrado que depende, sobretudo, de uma alteridade para se concretizar através das práticas comunicativas.

O último dos três pontos supracitados é desenvolvido mais cuidadosamente em um texto já paradigmático do sociólogo Louis Quéré (1995). No referido trabalho, o autor se propõe a delimitar uma abordagem comunicacional adequada à apreensão da atividade de organização social, estabelecendo a comunicação como lugar da constituição social dos fenômenos. Para Quéré, a comunicação diz respeito à modelagem de um mundo comum em meio a uma ação conjugada, que abarca a edificação de uma perspectiva comum. Tal perspectiva possibilita aos parceiros especificar a forma empregada para interagirem uns com os outros e com o mundo. Assim, constroem, "de maneira coordenada e de acordo com o modo do 'sentido encarnado', aquilo que eles tornam a si mesmos manifesto ou sensível na interação: a saber, uma maneira de se ligar, uma estrutura de expectativas recíprocas, um mundo e um horizonte comuns" (QUÉRÉ, 1995, p.118). Quando fala em perspectiva comum, esse autor, entretanto, alerta que ela não corresponde a uma concordância de pensamentos ou opiniões, muito menos a uma convergência de pontos de vista, mas sim à construção conjugada de um lugar comum a partir do qual ocorrerá uma relação de interlocutores, uma interlocução com o mundo e uma ordenação das ações recíprocas.

No desenrolar de seu artigo, Quéré (1995) elenca os ingredientes que configuram a noção de mundo comum edificado em uma situação comunicativa. Frisa que os elementos do ambiente se tornam visíveis em sua aparição na ação em curso, e que essa ação faz emergir seu mundo, com os primeiros planos e os horizontes, os estados de coisas e as esperas. Destaca também que a intenção é encarnada na ação que a exprime, ou seja, as intenções dos agentes não existem previamente à ação comunicativa. Elas adquirem sentido no curso da ação conversacional, e os interlocutores atribuem sentido às ações segundo a leitura dessas intenções manifestas.

Sobre a disposição dos agentes em comunicação, Quéré (1995) caminha na esteira de Jacques (1982) asseverando que os parceiros em uma interação se constituem reciprocamente como sujeitos da ação, com um espaço de intervenção e de responsabilidade recíprocas. Assim, cada situação de interação requer que uma relação seja construída como condição de possibilidade e componente de uma ação conjunta. "É na e pela maneira com que as pessoas configuram suas relações recíprocas na troca, que elas tornam mutuamente sensível ou manifesto o laço social que as une" (QUÉRÉ, 1995, p.123).

A perspectiva defendida por Quéré (nomeada por ele de paradigma praxiológico) aprecia o ambiente humano como real e objetivo, mas intrinsecamente condicionado por uma perspectiva comum edificada no seio de uma comunidade de linguagem e de ação que esse ambiente incorpora para sedimentar a identidade e a objetividade do mundo. Por essa guinada, os eventos são determinados em seu curso em interação com agentes 
dotados da capacidade de percepção, seleção e um poder de simbolização²; sendo assim, o caráter social das ações e dos acontecimentos é uma realização coordenada sob um terreno familiar e conhecido em comum com os outros.

Como ficou evidente, Dewey, Jacques e Quéré partilham, ainda que com gradações variadas, a definição de comunicação como atividade realizada conjuntamente, e fundam seu horizonte explicativo tomando por base essa decisão. A noção de comum à qual todos eles se referenciam, derivada da ideia de ação em comum oriunda da raiz etimológica de comunicação, norteia uma forma de lidar com as interações sociais que valoriza amplamente o modo como elas se desenham enquanto instâncias fulcrais na edificação de um mundo partilhado. Nesse sentido, o comum implicado na comunicação é o que permite a construção contextualmente coordenada e orientada de significância (DEWEY, 1980); o processo permanente de identificação pessoal decorrente da práxis relacional (JACQUES, 1982); a consolidação de um mundo comum ancorado nas práticas encarnadas dos envolvidos em construir a realidade social (QUÉRÉ, 1995).

Se a averiguação das potencialidades de apreensão do comum fosse encerrada nessa abordagem relacional da comunicação, as interações comunicativas poderiam ser tratadas como um ambiente no qual não haveria interposições de outras ordens que não aquelas responsáveis pela construção tentativa de propósitos, de ações e de identificações conjugadas que permitiram a resolução de necessidades práticas mobilizadas nos episódios de interação. Mas é notório o fato de que nem sempre todos os interlocutores agenciados em uma situação comunicativa são convocados a resolver as adversidades que envolvem a configuração de uma focalização em comum. Tal direito (ou ausência de direito) de intervenção na resolução compartilhada de crises em um ambiente de comunicação não é equivalente à discordância de opiniões entre parceiros que se reconhecem reciprocamente.

\section{A comunicação entre disjunções}

Algumas perspectivas teóricas têm debatido a definição de comunicação anteriormente apresentada e suas implicações no plano teórico, trazendo à baila, no processo, um significado complementar ao termo. Nöth (2011), em texto recente, retoma a etimologia da palavra para afirmar que communicare, em latim, não se traduz somente como um fazer comum, mas também como algo oposto, da ordem da divisão. Em suas palavras, "enquanto o prefixo com da palavra compartilhar implica a lógica da conjunção, o radical, partilhar, com a sua referência à ideia de partir implicando 'separação', pertence à lógica da separação" (NÖTH, 2011, p.87). Sendo assim, infere-se do argumento que tornar comum também implica uma disjunção, um movimento de separar-se ou desprender-se de algo, ou seja, abre-se terreno para uma tensão acerca do tipo de partilha inerente à práxis comunicativa.

2 Importante frisar que, para Quéré (1995), a linguagem é parte integrante da construção social da realidade, e serve aos agentes para articulação da experiência. Pela linguagem seria possível qualificar atos e os comportamentos de uns e de outros. 
As implicações dessa apreensão da noção de comunicação resgatada por Nöth (2011) são perceptíveis em autores contemporâneos que, mesmo abordando lateralmente a questão comunicacional com o propósito de enriquecer as reflexões que realizam em nível sociológico e/ou filosófico, tratam dos riscos de dissolução das interações mantidas que decorrem da abertura ao comum nas circunstâncias de interlocução (ainda que a comunicação seja a condição basilar para a transposição do isolamento) (ESPOSITO, 2003); ou ainda apontam que a coordenação conjunta de ações não deve ser superestimada, tendo em vista que em situações de disputa os atores se desconectam dos compromissos práticos que mantiveram um curso de ação partilhado (BOLTANSKI, 2009).

Entretanto, há outro campo de indagações acerca de uma abordagem relacional dos processos comunicativos que aciona essa chave interpretativa da disjunção muito embora não se proponha a enfrentar o tema relativizando o pressuposto de que há na práxis comunicativa um tipo de coordenação através de uma perspectiva em comum, e menos ainda se oriente em destacar as situações de impasse à deliberação no entorno de um assunto litigioso por sujeitos que se reconhecem mutuamente credenciados a atuar em uma situação de interação. O principal ponto de divergência, inspirado, sobretudo, pelas reflexões que pautaram a obra de Jacques Ranciére, incide em uma problematização da acepção de comum impressa em uma perspectiva relacional da comunicação, conduzindo o argumento no intento de sensibilizar sobre o lugar de disputa configurado na delimitação de quem pode ou não participar de um espaço partilhado de interlocução comunicativa (sem que haja uma restrição simplificadora entre privilegiados e desprivilegiados).

Mas se é razoável asseverar que nos trabalhos de Jacques Rancière há uma preocupação persistente em evidenciar como um suposto horizonte conjugado de referências não se delineia exclusivamente como um ponto de partida para a interação comunicativa, é de capital importância antes de tudo evidenciar como esse autor entende a comunicação, para então escrutinar as implicações dessa conceituação em uma guinada disjuntiva (ou dissensual, para empregar os termos utilizados por ele) do comum que pavimenta tal processo de interação social.

Em O Mestre Ignorante (2002), Rancière sugere que o processo comunicativo seria análogo a um ato de tradução: "Toda palavra, dita ou escrita, é uma tradução que só ganha seu sentido na contra tradução, na invenção das causas possíveis para o som que ouviu ou para o traço escrito: vontade de adivinhar que se apega a todos os indícios" (RANCIÈRE, 2002, p.73). Segundo o autor, essa vontade é o desejo de compreender e de se fazer compreender, que confere sentido à materialidade da linguagem. Mas a despeito desse esforço constante, a comunicação não garante mútua compreensão. Não há explicação que decifre perfeitamente o que o outro quer dizer e a verdade de suas intenções, é preciso adivinhar, rastrear. 
As palavras que se propagam nesse jogo de traduções são, para Rancière (2000), o que caracterizam o ser humano como ser político ${ }^{3}$. Mas se as pessoas podem pôr em circulação palavras que excedem a função de rígida designação, sempre existirão aquelas que irão reivindicar um direito natural de estabelecer o que pode ou não ser dito e da boca de quem as palavras devem mobilizar esse esforço de compreensão. Tal artifício de instauração da desigualdade entre sujeitos - que supostamente teriam as mesmas competências para se aventurar pelos gestos de tradução que instituem o ato comunicativo -, Rancière (2005) nomeia como partilha do sensível. Em termos sucintos, esse conceito aborda a vinculação entre uma experiência sensível e uma interpretação que faz com que ela adquira sentido. A partilha produz como resultado, nas palavras do autor, "um recorte dos tempos e dos espaços, do visível e do invisível, da palavra e do ruído" (RANCIÈRE, 2005, p.16), e faz ver "quem pode tomar parte no comum em função daquilo que faz, do tempo e do espaço em que essa atividade se exerce. Assim, ter essa ou aquela 'ocupação' define competências ou incompetências para o comum" (idem, p.16), ou seja, associar um sujeito a um tipo de atividade pode significar enquadrá-lo nas capacidades que são pressupostas que ele detenha ${ }^{4}$.

Rancière (2007) irá interrogar, por meio desse raciocínio, manifestações da presumida comunhão entre parceiros de um ato comunicativo edificadas em correlação ao ambiente que os acolhe. Ao se debruçar sobre a condição dos homens recém-libertos da escravidão em um contexto de reformas políticas na Grécia Antiga tratadas em A República de Platão, o autor irá recuperar o artificio que segundo ele o filósofo grego adotaria para justificar o afastamento desse povo (ou demos, como Rancière irá também nomear) das deliberações que envolviam a vida pública do período: afirmar que o demos não disporia de tempo para discutir política, pois estaria integralmente atrelado ao trabalho braçal. Racionalizando a desigualdade instituída com o argumento de que cada qual contribuiria para o bem comum a seu modo, é estabelecida uma divisão sensível entre aqueles que possuem como tarefa o pensamento e aqueles que não são considerados seres pensantes - não estando aptos à atividade intelectual.

Essa segmentação persiste, segundo Rancière, também na questão operária do século XIX que fora averiguada mais detidamente em A noite dos proletários (1988). Para os trabalhadores, a emancipação significaria reorganizar a partilha do sensível vigente evidenciando que eles "efetivamente se comunicam com todos em um espaço comum, que não são somente seres de necessidade, de queixa ou de grito, mas sim seres de razão e

3 Segundo Rancière, "a política ocupa-se do que se vê e do que se pode dizer sobre o que é visto, de quem tem competência para ver e qualidade para dizer, das propriedades do espaço e dos possíveis do tempo" (2005, p.17).

4 Rancière detalha da seguinte forma a lógica da explicação da desigualdade: "Eu explico uma frase a alguém porque suponho que essa pessoa não a compreenderia se não a explicasse. Ou seja, eu a explico que, se eu não a explicasse, ela não compreenderia. Em breve, eu a explico que é menos inteligente que eu e que é por isso que merece estar aí e eu onde estou. A relação social se sustenta em virtude dessa operação sem fim de consentimento" (RANCIÈRE, 2007, p.65). 
discurso, que podem opor razões as razões e esgrimir sua ação como uma demonstração" (RANCIÈRE, 2007, p.39).

Na esteira de Rancière, infere-se então que a configuração de um comum de ação coordenada em que os sujeitos já são de partida reconhecidos aptos a agir em comum serve, sobremaneira, ao apaziguamento dos dissensos ${ }^{5}$ inerentes à política e as práticas comunicativas. A organização do comum é o constante dano ${ }^{6}$ que permeia a atividade política, qual seja: se o lugar que os interlocutores ocupam na cena pública de interação não é problematizado, então existem parcelas que não são contabilizadas como parte efetiva de uma comunidade, ou seja, há sujeitos que (apesar de aparentemente considerados) são vistos como incapazes de oferecer contribuições significativas para o delineamento do comum.

Mas há uma contradição nessa forma de disposição do comum forjado através desse dano fundamental. Para dizer a um trabalhador que ele não tem como tarefa o pensamento é preciso explicar a ele a lógica que governa a distinção entre os pensantes e os não pensantes, e isso implicará que esse trabalhador reflita para entender o argumento formulado, traduzindo para si o raciocínio que não deveria ser de sua posse. A conclusão de Rancière (2007) é que para afirmar a desigualdade é preciso pressupor a igualdade. Portanto, a condição de equidade que os sujeitos partilham decorrente de sua capacidade de efetuar traduções e se compreenderem ao comunicarem, corrói toda a ordem natural que divide o comum entre partes hierarquizadas, expondo sua contingência última. Nas palavras do autor, "é precisamente porque nós somos todos iguais por natureza que devemos ser todos desiguais pelas circunstâncias" (RANCIÈRE, 2002, p.96).

Para Rancière, a subversão à forma ordenada de distribuição do sensível implica o reenquadramento de um comum constituído, tornando-o uma dimensão submetida à verificação através da enunciação de um dano existente. Ao nomear um dano é exposto um intervalo ou uma falha que permite a demonstração política da ausência de igualdade que gera o dano. Nessa cena se exprime a falha na ordem social em reconhecer a igualdade que deveria existir entre as partes que integram o comum em um processo comunicativo. Essa ação pode se configurar, primeiramente, como o momento em que se dá a formação do sujeito como interlocutor capaz de tornar objeto de debate aquilo que é recriminado. Em seguida, como oportunidade de reinventar a cena comunicativa polêmica na qual os atores tentam se inscrever, e como oportunidade de enriquecer a linguagem que utilizam, de inverter papéis e até mesmo de silenciar os que geralmente falam para deixar falar aqueles que, a princípio, não teriam nada a dizer.

5 O dissenso "não é o conflito entre interesses, mas sobre o que é um interesse, sobre quem é visto como capaz de lidar com interesses sociais e aqueles que deveriam supostamente ser capazes de reproduzir sua vida" (RANCIÈRE, 2011, p.2).

6 Segundo Rancière, o conceito de dano (tort) diz respeito ao "modo de subjetivação no qual a verificação da igualdade adquire figura política" (1996, p.51). 
Percebe-se pela lógica de expressão do dano que a igualdade no pensamento de Rancière toma forma através de uma enunciação performativa, prática. Ela é descrita como uma forma de relação constantemente sujeita à verificação, uma vez que questiona a distribuição desigual dos lugares e tempos a serem ocupados pelos sujeitos (resgatando o direito deles de se aventurarem pelas traduções que fazem fluir o processo comunicativo). Por essa razão, o ato de verificação da igualdade envolve a ação criativa e poética de evidenciar, nas partilhas até então traçadas (isto é, as distribuições do visível, do audível e do enunciável), os hiatos que a junção (a distribuição não problemática dos interlocutores em uma situação de fala) pretende apagar, de modo a permitir a instauração das cenas polêmicas. A verificação pragmática da igualdade cria determinadas situações de fala e de diálogo que não existiam previamente. Essas situações tornam possível o aparecer dos sujeitos como seres situados entre dois mundos, duas lógicas: uma em que são iguais por compreenderem o raciocínio daqueles que os consideram inaptos à compreensão; e outra em que são desiguais por não serem tidos em conta como seres comunicativos (tradutores em potência) devido à sua ocupação funcional ou ao seu lugar depreciado na hierarquia social.

Nos episódios interacionais, "a formação das cenas de dissenso requer, portanto, uma ação comum através da linguagem e da comunicação, de modo a promover não formas de 'ser em comum' (que apagam ou incorporam diferenças), mas formas de 'aparecer em comum'" (MARQUES, 2013, p.138). Desse modo, é possível afirmar que um mundo comum nunca é simplesmente um ethos, a estadia comum, mas é também a partilha do que ainda não está dado como em-comum, "a distribuição polêmica das maneiras de ser e das 'ocupações' num espaço de possíveis" (RANCIÈRE, 2005, p.59).

Percebe-se que a agonística comunicacional em Rancière é investida em uma poética da fabulação das cenas, da emergência de mundos nos quais sujeitos e objetos antes desconsiderados se tornam visíveis e audíveis. Nesses termos, a ação política diz respeito à proposição de contextos e de situações comunicativas que constroem as posições dos sujeitos em um cenário que não é dado de antemão. Em outras palavras, a interlocução política se desenvolve precisamente em situações nas quais nenhuma cena existia a priori para regular os parceiros de interlocução ou as questões pertencentes ao domínio do comum. É na instauração de tais cenas polêmicas que se criam situações aptas a modificar o olhar e as atitudes com relação ao ambiente coletivo, já que, nestes instantes, a naturalidade de um tipo de ordem é posta em questão e em suspensão (um modo de encarnação dos atores em ação, uma distribuição dos papeis e de padrões de coordenação da ação comunicativa).

Rancière admite que a criação de cenas polêmicas refere-se a capacidades enunciativas e demonstrativas de reconfigurar a relação entre o visível e o invisível, entre a norma e o fato, entre o dizível e o silenciável, entre discursos e corpos, mas também corresponde às competências emancipatórias, de afastamento de uma identificação imposta de fora (que determina os locais a serem ocupados pelos sujeitos em função 
de sua posição na hierarquia social), em prol de um conhecimento de si. Como Rancière (2011) argumenta, essa forma de saber diz respeito à consciência que o sujeito toma do papel que assumira até então na ordem social, permitindo-se problematizar o destino que the fora incumbido como forma de vida. Abre-se caminho para o surgimento de identificações impossíveis que, segundo o autor, desafiam as lógicas vigentes de contagem de corpos em comum, expondo percursos alternativos para que os sujeitos assumam posições que até então lhes eram inacessíveis - ou ainda definindo para si mesmos o direito de existir para além dos meios de identificação predominantes.

A ação política é então a constante (re)invenção de uma cena polêmica de enunciação, emancipação e interlocução na qual se inscreve a palavra do sujeito falante, e na qual esse próprio sujeito se constitui "capaz de se pronunciar em primeira pessoa e de identificar sua afirmação com a reconfiguração de um universo de possibilidades" (RANCIÈRE, 2011, p.13). Tais capacidades, que decorrem da instauração em ato de uma comunicação que delineia um horizonte comum provisório (uma cena polêmica de verificação/disjunção em face de um comum hierarquizado e restritivo), lançam um desafio à oposição entre falantes legítimos e ilegítimos, permitindo que o mundo comum da experiência seja redesenhado, além de desvelar trilhas para que sujeitos possam construir-se, escolher e levar a termo um projeto de vida sob formas impensáveis segundo os códigos hegemônicos de interação e de coordenação da ação.

\section{Considerações finais}

Ao longo desse artigo, foi possível contrastar, através da recuperação da etimologia do termo comunicação, duas formas de compreensão da palavra que acenam para leituras distintas das práticas interacionais. De um prisma, priorizou-se uma interpretação relacional da comunicação enquanto processo, interpretação essa que tem como espinha dorsal um entendimento da práxis interacional, notadamente, como ação em comum na qual são instituídos significados, interlocutores e uma perspectiva de acesso ao mundo social in situ. Já a segunda visada reconstituída interpõe à partilha formulada por essa concepção de comunicação (e sob uma apreciação etimológica distinta) não só as obstruções e os riscos que permeiam os processos de coordenação de ações em comum, mas acima de tudo se esmera em lançar luz ao fato de que a interdição à expressão de atores em uma situação comunicativa não é uma exceção derivada de uma reciprocidade distorcida (deslocada do princípio partilhado das práticas), mas uma dimensão de fundamental importância para o entendimento do modo como o mundo comum se modela e da forma como seus sujeitos ganham o status de parceiros dignos.

Importante reforçar que o percurso argumentativo desse artigo não procurou sugerir uma superação e consequente abandono do viés relacional dos estudos em Comunicação em prol de outra abordagem, mas sim foi conduzido no ímpeto de estimular o debate 
oferecendo novos horizontes heurísticos para as pesquisas desenvolvidas no campo. Para além desse esforço, destaca-se, em afinação a Braga (2007), que se em uma conjuntura de ascendente midiatização dos processos interacionais artifícios tecnológicos e operacionais atrelados às práticas já constituídas de interação podem ora incrementar um quadro de deslegitimação de determinados interlocutores potenciais, ora abrir possibilidades para que estes sujeitos participem das cenas sociais e construam novos vínculos, parece fundamental, nesse cenário, renovar a visada crítica nos estudos em Comunicação. Nesse sentido, a leitura disjuntiva do comum impresso na práxis comunicativa parece favorecer o empreendimento, oferecendo subsídios teóricos complementares às tradições já consolidadas de investigação.

\footnotetext{
Thales Vilela Lelo é doutorando em Ciências Sociais pela UNICAMP e mestre em Comunicação Social pela UFMG. É membro do Grupo de Pesquisa "Jornalismo, Narrativas e Práticas Comunicacionais" (UFOP) e do Grupo de Estudos "Trabalho, Saúde e Subjetividade" (UNICAMP).

thales.lelo@gmail.com
}

\section{Referências}

BOLTANSKI, L. On Critique: a sociology of emancipation. Cambridge: Polity Press, 2009.

BRAGA, J. Mediatização como processo interacional de referência. In: MÉDOLA, A.; ARAÚJO, D.; BRUNO, F. (Orgs). Imagem, visibilidade e cultura midiática. Porto Alegre: Sulina, 2007, pp.141-167.

BUBER, M. EU e TU. São Paulo, Centauro, 2003.

DEWEY, J. Natureza, comunicação e significado. In: DEWEY, J. Os Pensadores. São Paulo: Abril Cultural, 1980, pp. 29-52.

ESPOSITO, R. Communitas: origen y destino de la comunidad. Buenos Aires: Amorrortu, 2003.

JACQUES, F. Différence et Subjetivité. Paris: Éditions Aubier Montaigne, 1982.

MARQUES, A. Relações entre comunicação, estética e política a partir das abordagens conceituais de Habermas e Rancière. In: Fronteiras, v.15, n.3, 2013, pp. 150-159.

MARTINO, L. De qual comunicação estamos falando? In: HOHLFELDT, A; MARTINO, L. e FRANÇA, V. (Orgs.). Teorias da comunicação: escolas, conceitos e tendências. Petrópolis: Vozes, 2001, pp.11-25.

NÖTH, W. Comunicação: os paradigmas da simetria, antissimetria e assimetria. In: MATRIZES, n.1, pp.85-108.

QUÉRÉ, L. From an epistemological model of communication to a praxeological approach. In: Réseaux, v.3, Paris: Tekhné, 1995, pp. 111-133.

RANCIÈRE, J. A noite dos proletários. Arquivos do sonho operário. São Paulo: Companhia das Letras, 1988.

O desentendimento: política e filosofia. São Paulo: Editora 34, 1996. 
interview to PANAGIA, D. Dissenting words: a conversation with Jacques Rancière. In: Diacritics, v.30, n.2, 2000, pp.113-126.

. O mestre ignorante: cinco lições sobre emancipação intelectual. Belo Horizonte: Autêntica, 2002. A partilha do sensível: estética e política. São Paulo: EXO Experimental, 2005.

En los bordes de lo político. Buenos Aires: Ediciones la Cebra, 2007.

. The thinking of dissensus: politics and aesthetics. In: BOWMAN, P; STAMP, R. (Orgs.). Reading Rancière. London: Continuum International Publishing Group, 2011, pp. 1-17.

THOMPSON, J. A mídia e a modernidade: uma teoria social da mídia. Petrópolis: Vozes, 2009.

WILLIAMS, R. Palabras Clave: Un vocabulario de la cultura y de la sociedad. Buenos Aires: Nueva Visión, 2003.

WINKIN, Y. A Nova comunicação. Da teoria ao trabalho de campo. São Paulo: Papirus, 1998. 